\title{
Role of imprint cytology in intraoperative diagnosis: value and limitations
}

\author{
K. C. SUEN, W. S. WOOD, A. A. SYED, N. F. QUENVILlE, AND \\ P. B. CLEMENT
}

From the Division of Surgical Pathology, Department of Pathology, Vancouver General Hospital, University of British Columbia, Vancouver, BC, Canada

SUMMARY Imprints prepared from fresh surgical specimens give excellent cytological clarity. Used intraoperatively, the imprint method can provide valuable information when frozen-section inter-s pretation is equivocal. However, cytologically well-differentiated tumours and tumours with a denseci. fibrous stroma, constituting $6 \%$ of the cases in the present series, cannot be diagnosed by this $\infty$ method. To increase diagnostic accuracy we recommend the combined use of imprints and frozeno sections. The imprint technique requires little additional work and does not delay the frozensection procedure.

The use of frozen sections for intraoperative tissue diagnosis is a well-accepted procedure (Ackerman and Ramirez, 1959; Nakazawa et al., 1968; Shivas and Fraser, 1971; Holaday and Assor, 1974). Another method is the examination of imprints of fresh specimens. This technique was favourably reported by Dudgeon and Patrick (1927) and Bamforth and Osborn (1958), but not until recently has it achieved the recognition it deserves in the English literature (Pickren and Burke, 1963; Tribe, 1965; Godwin, 1968; Silverberg, 1975; Suen et al., 1976; Godwin, 1976). Despite its simplicity, speed, and excellent cellular detail, we believe many centres are still not utilising the technique to its fullest extent. The lack of quantitative analysis of large series of imprint materials in the literature prompts us to report our experience with this method, especially with regard to the merits and pitfalls in the diagnosis of malignant tumours. We will emphasise those situations in which the technique has been found to be most useful.

\section{Method and materials}

A direct imprint is prepared by pressing a glass slide gently on to the freshly cut surface of the specimen, avoiding a gliding movement, which will distort the shape of the cells. The imprint slide is immediately fixed in $95 \%$ ethyl alcohol for 5-6 seconds and then stained (rapid haematoxylin and eosin). The entire procedure is completed during the freezing period of

Received for publication 5 October 1977 the tissue preparation; thus there is no delay in the completion of the frozen section. Depending on one s: preference, a rapid polychrome dye, such as toluidines blue, can also be used on heat-fixed slides. This would further shorten the preparation time, but the differential colour of the preparation is not as good as that of a slide stained with haematoxylin and eosin.

During the 17-month period from November 1974 to March 1976, 1306 surgical specimens (excludingo neurosurgical specimens) were submitted intra operatively for rapid tissue diagnosis. Imprints and frozen sections were prepared simultaneously frone 1258 of the 1306 specimens. On average two imprints per case were prepared and examined beforeo the examination of the frozen sections. Frozen section technique was the method of choice in the remaining 48 cases, including the 38 specimens sub $\rightarrow$ mitted for evaluation of resection margins and 10 ? specimens from patients suspected of Hirschsprung's disease, in which ganglion cells had to be searched for carefully.

\section{Results}

Table 1 shows the imprint results of the 1258 cases tabulated according to organ site. The accuracy of? the imprint method was assessed by comparing the imprint diagnosis with the corresponding paraffin $\overrightarrow{0}$ section diagnosis. The overall accuracy rate for this method was $93.8 \%$, with a false-negative rate of $6 \%$ and a false-positive rate of $0.24 \%$. The 77 false 
Table 1 Imprint results of 1258 surgical specimens

\begin{tabular}{|c|c|c|c|c|}
\hline \multirow[t]{2}{*}{ Site } & \multicolumn{2}{|c|}{ Diagnoses } & \multirow[t]{2}{*}{ False negative } & \multirow[t]{2}{*}{ False positive } \\
\hline & Total & Correct & & \\
\hline Breast & 473 & . & & \\
\hline Carcinoma & 203 & $183(90)$ & $20(10)$ & \\
\hline Benign nontumour & 191 & $191(100)$ & & \\
\hline Benign tumour & 75 & $75(100)$ & & \\
\hline Miscellaneous & 4 & $4(100)$ & & \\
\hline Lymph node & 198 & & & \\
\hline Metastatic carcinoma & 46 & $44(96)$ & $2(4)$ & \\
\hline Lymphoma & 17 & $15(88)$ & $2(12)$ & \\
\hline Granuloma & 16 & $10(63)$ & $6(37)$ & \\
\hline Reactive/normal & 119 & $118(99)$ & & $1(1)$ \\
\hline Lung & 84 & & & \\
\hline Tumour & 49 & $48(98)$ & $1(2)$ & \\
\hline Granuloma & 15 & $11(73)$ & $4(27)$ & \\
\hline Nongranulomatous inflammation & 20 & $20(100)$ & & \\
\hline Gastrointestinal & 70 & & & \\
\hline Tumour & 35 & $33(91)$ & $3(9)$ & \\
\hline Benign polyp & 8 & $8(100)$ & & \\
\hline Benign nontumour & 27 & $27(100)$ & & \\
\hline Liver & 29 & & & \\
\hline Carcinoma & 17 & $16(94)$ & $1(6)$ & \\
\hline Nontumour & 12 & $12(100)$ & & \\
\hline Pancreas & 11 & & & \\
\hline Carcinoma & 6 & $6(100)$ & & \\
\hline Inflammation & 5 & $5(100)$ & & \\
\hline Gallbladder & 9 & & & \\
\hline Carcinoma & 3 & $3(100)$ & & \\
\hline Cholecystitis & 6 & $6(100)$ & & \\
\hline Thyroid & 39 & & & \\
\hline Carcinoma & 12 & $5(42)$ & $7(58)$ & \\
\hline Adenoma & 4 & $4(100)$ & & \\
\hline Goitre and thyroiditis & 23 & $22(96)$ & & $1(4)$ \\
\hline Parathyroid* & 64 & & & \\
\hline Parathyroid & 47 & $47(100)$ & & \\
\hline Lymph node & 9 & $9(100)$ & & \\
\hline Thyroid fragment & 5 & $5(100)$ & & \\
\hline Adipose tissue & 3 & $3(100)$ & & \\
\hline Salivary gland & 29 & & & \\
\hline Benign mixed tumour & 13 & $13(100)$ & & \\
\hline Malignant mixed tumour & 1 & $1(100)$ & & \\
\hline Carcinoma, other types & 2 & $2(100)$ & & \\
\hline Warthin's tumour & 6 & $6(100)$ & & \\
\hline Sialadenitis & 4 & $4(100)$ & & \\
\hline Lymph node, intraparotid & 3 & $3(100)$ & & \\
\hline Bone & 28 & & & \\
\hline Primary malignant tumour & 8 & $8(100)$ & & \\
\hline Metastatic carcinoma & 4 & $4(100)$ & & \\
\hline Giant-cell osseous lesions' & 10 & $10(100)$ & & \\
\hline Hodgkin's disease & 1 & $1(100)$ & & \\
\hline Benign nontumour & 5 & $5(100)$ & & \\
\hline Soft tissue & 39 & & & \\
\hline Sarcoma & 6 & $5(83)$ & $1(17)$ & \\
\hline Lymphoma & 2 & $2(100)$ & & \\
\hline Benign lesion & 31 & $26(84)$ & $5(16)$ & \\
\hline Ovary & 57 & & & \\
\hline Carcinoma & 14 & $12(86)$ & $2(14)$ & \\
\hline Cystadenoma, borderline malignancy & 3 & & $3(100)$ & \\
\hline Benign tumour and cyst & 36 & $34(94)$ & $2(6)$ & \\
\hline Benign nontumour & 4 & $4(100)$ & & \\
\hline Uterus & 27 & & & \\
\hline Malignant tumour & 7 & $6(86)$ & $1(14)$ & \\
\hline Benign tumour & 9 & $9(100)$ & & \\
\hline Benign endometrium & 11 & $11(100)$ & & \\
\hline Prostate & 22 & & & \\
\hline Carcinoma & 6 & $4(67)$ & $2(33)$ & \\
\hline Benign hypertrophy & 16 & $15(94)$ & & $1(6)$ \\
\hline Urinary tract & 25 & & & \\
\hline Carcinoma & 15 & $15(100)$ & & \\
\hline Benign lesion & 10 & $10(100)$ & & \\
\hline Testis & 11 & & & \\
\hline Malignant tumour & 2 & $2(100)$ & & \\
\hline Adenomatoid tumour & 1 & $1(100)$ & & \\
\hline Benign nontumour & 8 & $8(100)$ & & \\
\hline
\end{tabular}


Table 1 (continued)

\begin{tabular}{lccc}
\hline Site & \multicolumn{2}{c}{ Diagnoses } & False negative \\
\cline { 2 - 3 } & Total & Correct & \\
\hline Skin & 25 & & \\
Squamous carcinoma & 3 & $2(67)$ & $1(33)$ \\
Melanoma & 5 & $5(100)$ & $5(62)$ \\
Basal-cell carcinoma & 8 & $3(38)$ & $7(78)$ \\
Other skin lesion & 9 & $2(22)$ & $2(11)$ \\
Miscellaneous & 18 & $16(89)$ & $77(6)$
\end{tabular}

*Imprints used to distinguish parathyroid glands from other specimens submitted as possible parathyroid tissue (ie, lymph node, thyroid, and adipose tissue)

Percentages are given in parentheses

Table 2 Distribution of 77 false-negative cases

\begin{tabular}{lcc}
\hline Site & \multicolumn{2}{l}{ Cases } \\
\cline { 2 - 3 } & No.negative/Total & Percent \\
\hline Liver & $1 / 29$ & $3 \cdot 5$ \\
Uterus & $1 / 27$ & $3 \cdot 7$ \\
Breast & $20 / 473$ & $4 \cdot 2$ \\
Gastrointestinal & $3 / 70$ & $4 \cdot 3$ \\
Lymph node & $10 / 198$ & $5 \cdot 0$ \\
Lung & $5 / 84$ & $6 \cdot 0$ \\
Prostate & $2 / 22$ & $9 \cdot 1$ \\
Miscellaneous & $2 / 18$ & $11 \cdot 1$ \\
Ovary & $7 / 57$ & $12 \cdot 3$ \\
Soft tissue & $6 / 39$ & $15 \cdot 4$ \\
Thyroid & $7 / 39$ & $17 \cdot 9$ \\
Skin & $13 / 25$ & $52 \cdot 0$ \\
& & \\
\hline
\end{tabular}

Note: There were no false negatives in imprints of the pancreas, gall bladder, salivary gland, parathyroid gland, urinary tract, testis, or bone.

negative cases are listed in Table 2. There were no false negatives in imprints of the pancreas, gall bladder, salivary gland, parathyroid gland, urinary tract, testis, or bone. The false-negative rate was within an acceptable range $(3.5-6 \%)$ in imprints of the liver, uterus, breast, gastrointestinal tract, lymph node, and lung. The false-negative rate was high $(9 \cdot 1-52 \%)$ in imprints of the prostate, ovary, soft tissue, thyroid, and skin. But the latter group comprised only 200 cases, that is, $16 \%$. The three false positives found among the 1258 cases occurred in thyroid, prostate, and lymph node.

In the course of this study, the imprint technique was found to be particularly valuable in the following situations:

IN THE DIAGNOSIS OF CERTAIN NEOPLASTIC

LESIONS WHICH CAN SIMULATE

INFLAMMATORY LESIONS ON FROZEN

SECTION

Many references in the literature (Nakazawa et al., 1968; Ackerman and Rosai, 1974; Holaday and Assor, 1974) attest to the difficulties in the frozensection diagnosis of pancreatic carcinoma. It poses a diagnostic problem when the growth pattern of a well-differentiated adenocarcinoma simulates that of benign, but distorted, ducts seen in chronic fibrosing pancreatitis. In our experience, imprint examination is often able to clear up a questionable frozen-section diagnosis. All of the six cases of pancreatic carcinoma encountered in this study (Table 1) showed unequivocal malignant cells on the imprints (Fig. 1).

Diagnosis of metastatic carcinoma in lymph node by frozen section presents no problem in the vast majority of cases. However, signet-ring cell carcinoma in lymph node can be mistaken for reactive sinus histiocytosis on frozen section (Fig. 2a). All three such cases in our study showed carcinoma cells on the imprints (Fig. 2b).

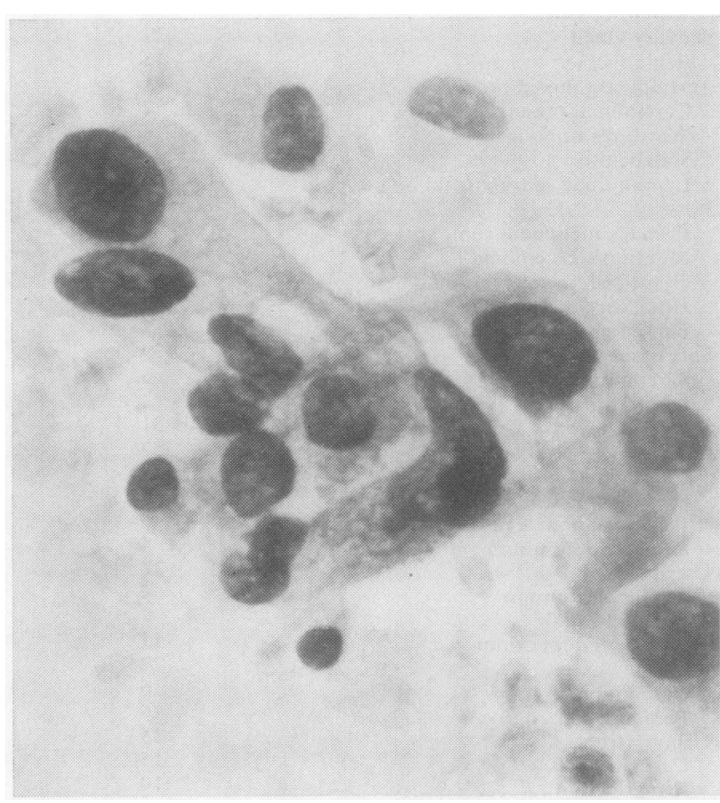

Fig. 1 Imprint of a well-differentiated pancreatic ductal carcinoma showing unequivocal malignant cells. (Haematoxylin and eosin $\times 365$ ) 


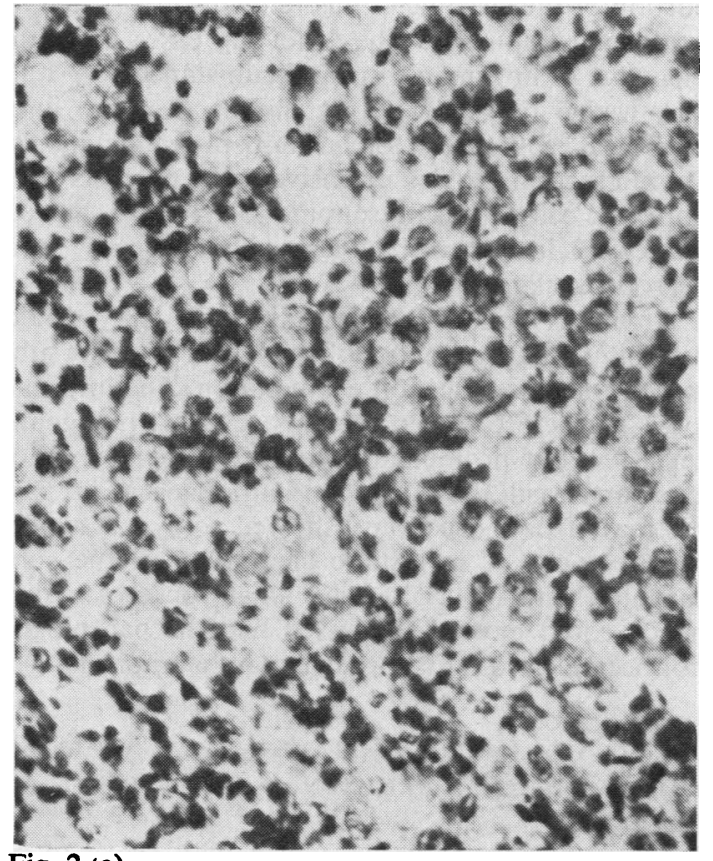

Fig. 2 (a)
IN THE DIAGNOSIS OF CERTAIN BENIGN INFLAMMATORY LESIONS WHICH CAN SIMULATE MALIGNANCY ON FROZEN SECTION

Inflammatory cells growing between connective tissue bundles in cases of organising pneumonia can simulate the growth pattern of an anaplastic carcinoma (Ackerman and Ramirez, 1959). Our experience shows that imprints are invaluable in view of the excellent cytological clarity (Fig. 3).

Intense sinus histiocytosis in lymph node can simulate metastatic carcinoma. Holaday and Assor (1974) reported a false-positive case because of misinterpretation of this histological picture on frozen section. Again, such errors can be avoided since the benign appearance of the histiocytes is better appreciated on imprints than on frozen sections.

IN THE DIAGNOSIS OF MALIGNANCY CONFINED TO ONE SMALL AREA OF A LARGE SPECIMEN

The amount of tissue that can be frozen for rapid intraoperative diagnosis is limited. On the other hand, the imprint technique can easily cover a larger

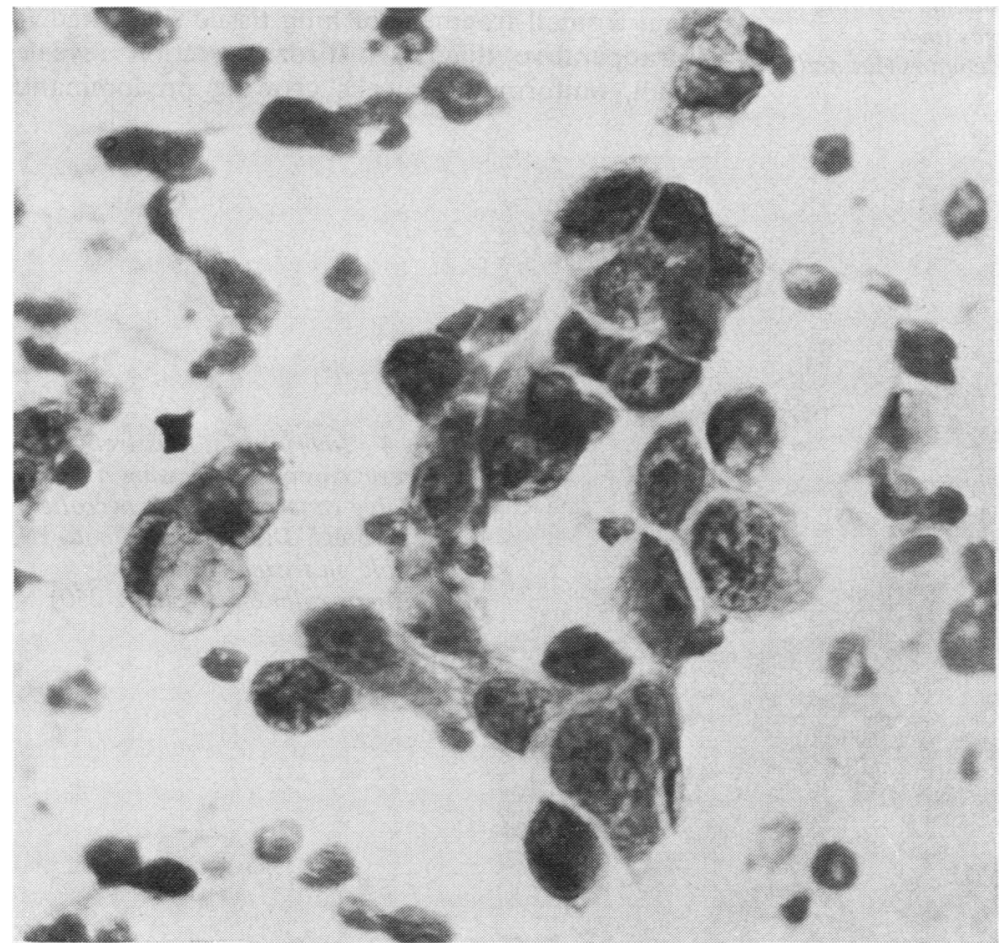

Fig. 2 (a) Frozen section of a lymph node infiltrated by signet-ring cell carcinoma mimicking sinus histiocytosis. (Haematoxylin and eosin $\times 220$ ) (b) Imprint of same node demonstrating better detail of the malignant signet-ring cells. (Haematoxylin and eosin $\times 400$ )

Fig. 2 (b) 


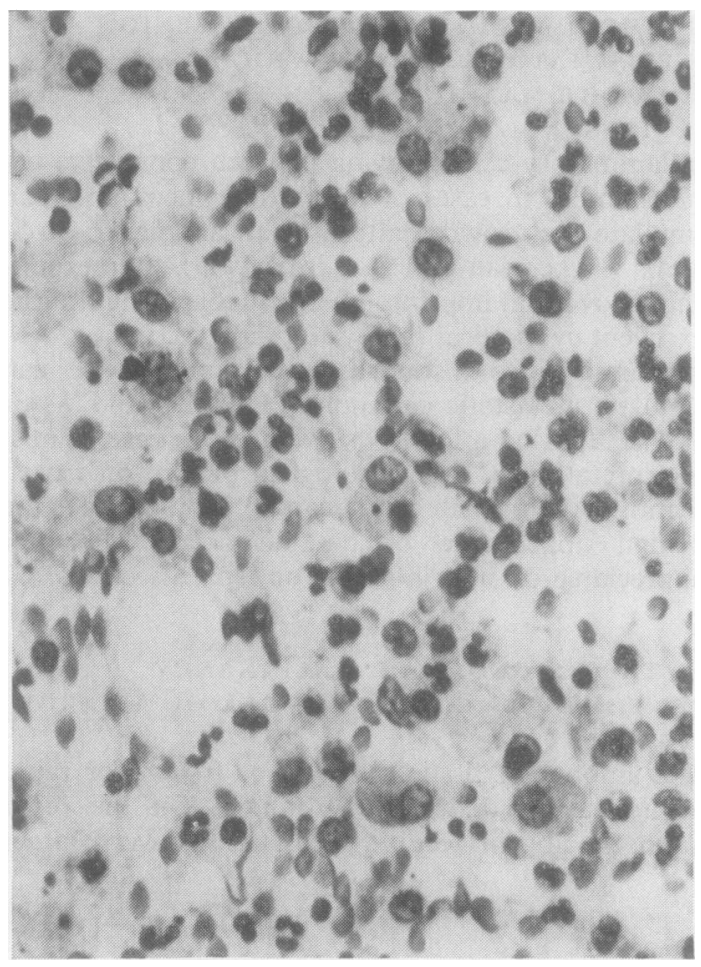

Fig. 3 Imprint of an organising pneumonia showing numerous benign appearing macrophages and leucocytes but no malignant cells. (Haematoxylin and eosin $\times 400)$ portion of the specimen, thus reducing errors due to inadequate sampling. The following cases illustrate the value of imprints in such circumstances:

A wedge biopsy of an extensively necrotic lung mass was submitted for intraoperative diagnosis. Frozen section showed extensive tissue necrosis with no viable cells. Imprint examination (Fig. 4) showed scattered clusters of viable malignant cells in a necrotic background.

An apical axillary lymph node from a 43-year-old woman with a carcinoma of the left breast was submitted for frozen-section examination. The imprints available before frozen sections revealed malignant cells, few but prominent among the small lymphocytes and easily noted by the pathologist (Fig. 5a); whereas frozen sections showed only a single, minute focus of metastatic carcinoma in the subcapsular sinus (Fig. 5b). This small focus of malignancy could have been missed had the pathologist not been alerted by its presence on the imprints.

\section{IN THE DIAGNOSIS OF MALIGNANCY WHEN THE SUBMITTED SPECIMEN IS LIMITED IN QUANTITY}

Small fragments of tissue, which may prove to be difficult for frozen-section interpretation, are often large enough to provide sufficient cells for imprint interpretation. Figure 6 shows an imprint prepared from a small fragment of lung tissue submitted for intraoperative diagnosis. Frozen section revealed small, uniform, dark cells growing predominantly

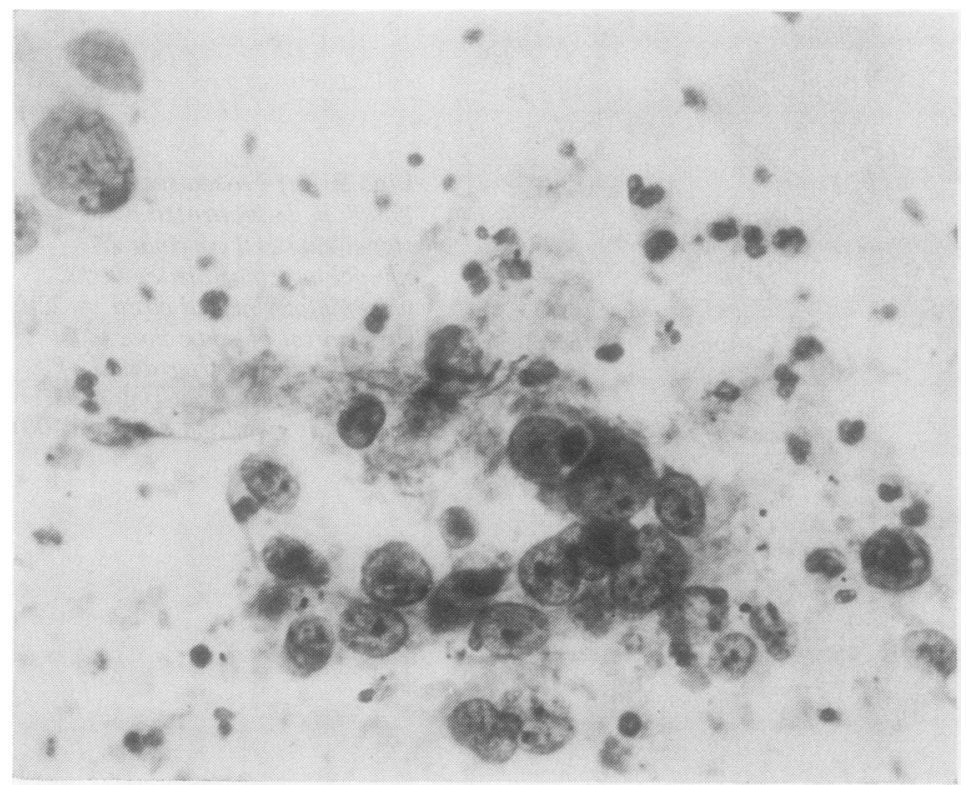

Fig. 4 Imprint of a massively necrotic carcinoma showing a cluster of viable cancer cells on a necrotic background. Diagnosis was not possible on frozen section. (Haematoxylin and eosin $\times 250$ ) 


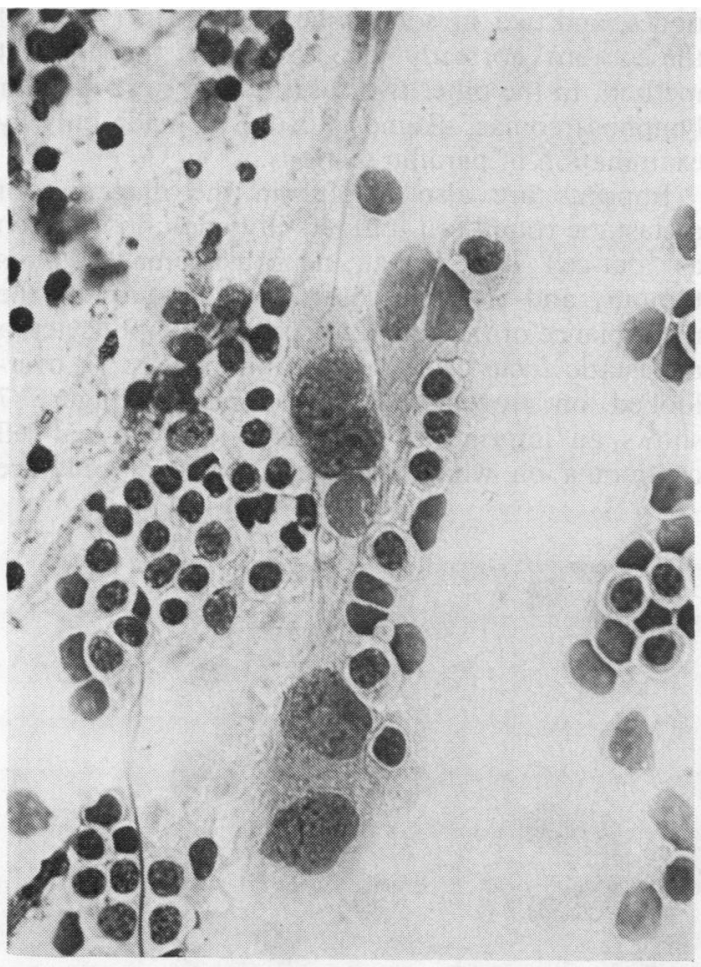

Fig. 5 (a)

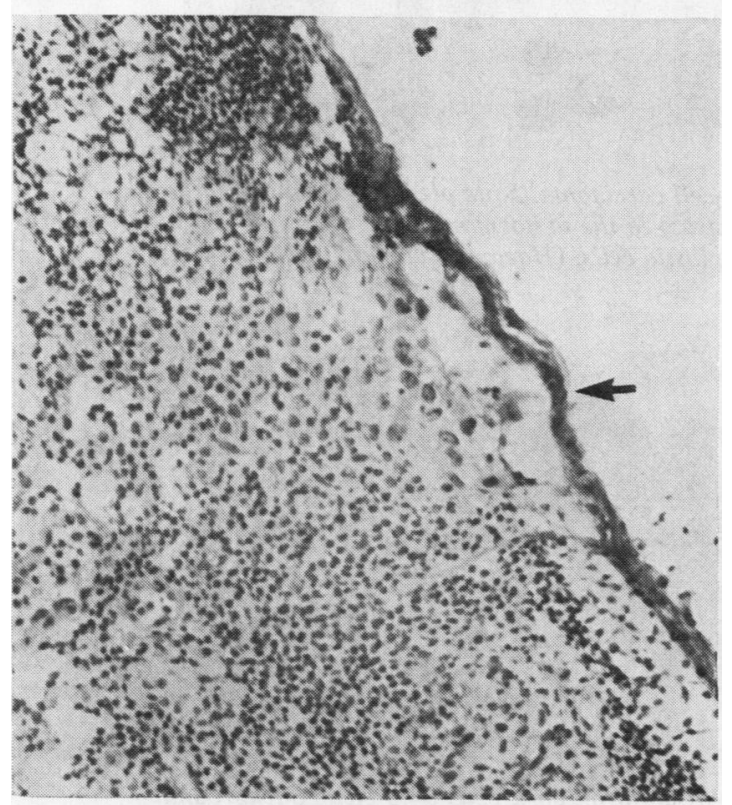

Fig. 5 (b)
Fig. 5 (a) Imprint of a lymph node showing malignant cells. (Haematoxylin and eosin $\times 400$ ); (b) Frozen section of same node showing a single microscopic focus of mammary carcinoma (arrow) in the subcapsular sinus. (Haematoxylin and eosin $\times 250)$

Fig. 6 Imprint of a small fragment of lung tissue revealing uniform cells with rosette-like formations suggestive of a carcinoid tumour. (Haematoxylin and $e o s i n \times 250)$

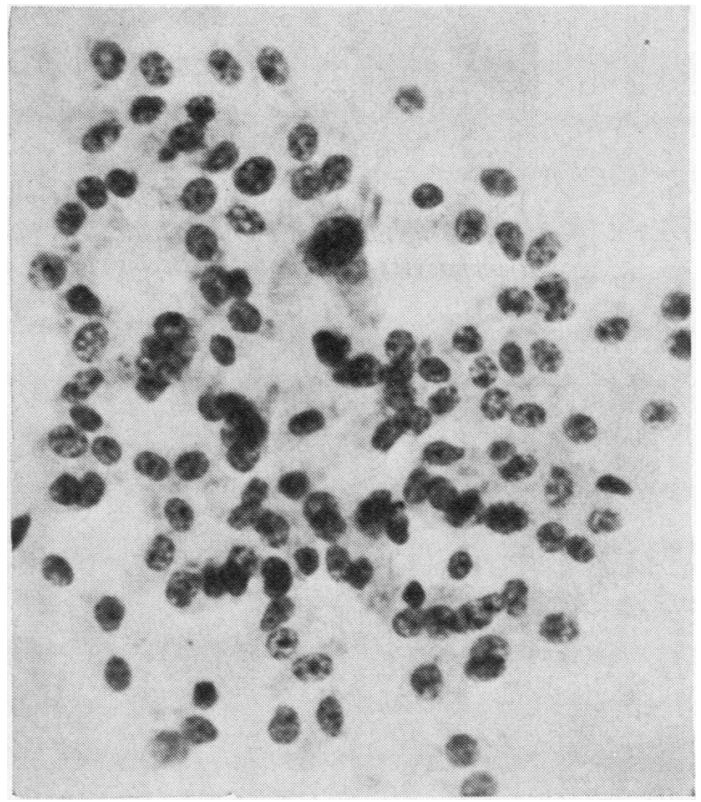

Fig. 6 
along the alveolar septa, giving no indication as to whether they were inflammatory or neoplastic in origin. Imprint examination showed scattered groups of small, uniform cells forming rosette-like structures, suggesting the neoplastic nature of these cells, that is, a carcinoid tumour of the lung.

\section{IN THE DIAGNOSIS OF MALIGNANT}

LYMPHOMA AND OTHER SMALL ROUND-CELL TUMOURS IN LYMPH NODE HISTOLOGICALLY CONFUSED WITH LYMPHOMA

Malignant lymphomas are more readily diagnosed by the imprint method. There were 19 cases of malignant lymphoma in the present series, 17 in lymph nodes, and two in soft tissue. Seventeen ( $90 \%$ ) of these were correctly diagnosed by the imprint method. In the other two cases, which were nodular lymphosarcomas, diagnosis could be made only by examination of paraffin sections.

Imprints are also helpful in the diagnosis of metastatic round-cell tumours in lymph nodes, such as oat-cell carcinoma, neuroblastoma, Wilm's tumour, and rhabdomyosarcoma. Because of the resemblance of the neoplastic cells to lymphocytes, a metastatic focus from such tumours may be overlooked on frozen-section examination. Figure 7 shows an imprint of a lymph node with oat-cell carcinoma on which two populations of cells are

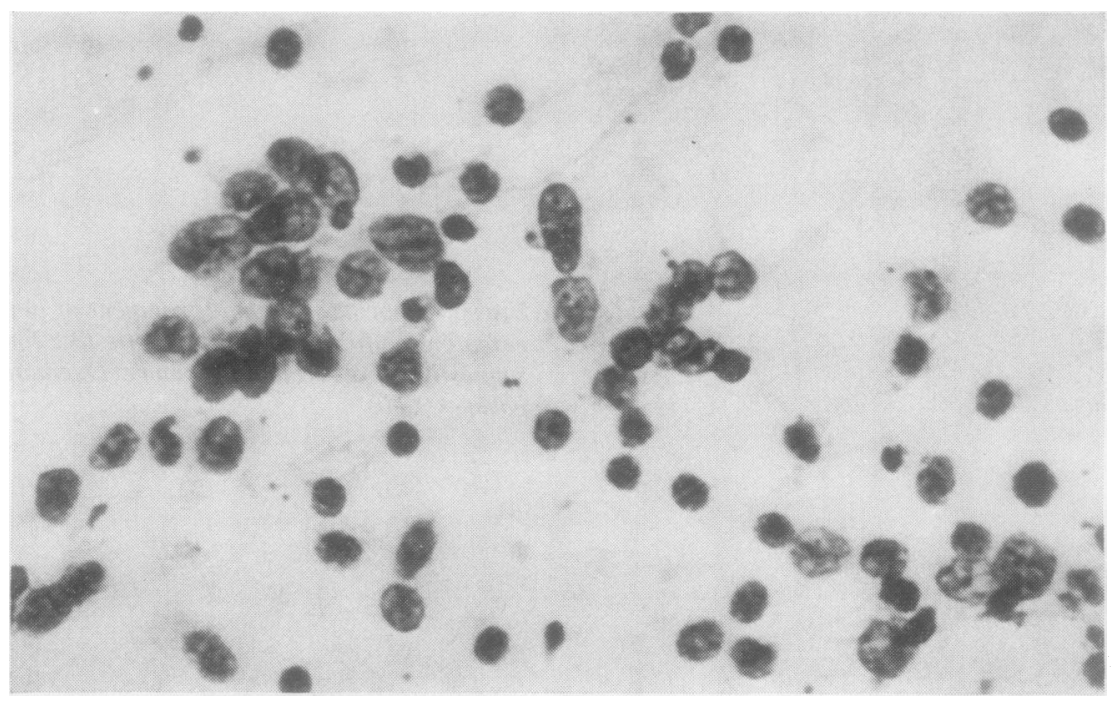

Fig. 7 Imprint of a lymph node showing oat-cell carcinoma. Note pleomorphism and large size of the nuclei of the neoplastic cells in contrast to the uniform nuclei of the lymphocytes. Also note 'clustering' of the neoplastic cells. (Haematoxylin and eosin $\times 400$ )

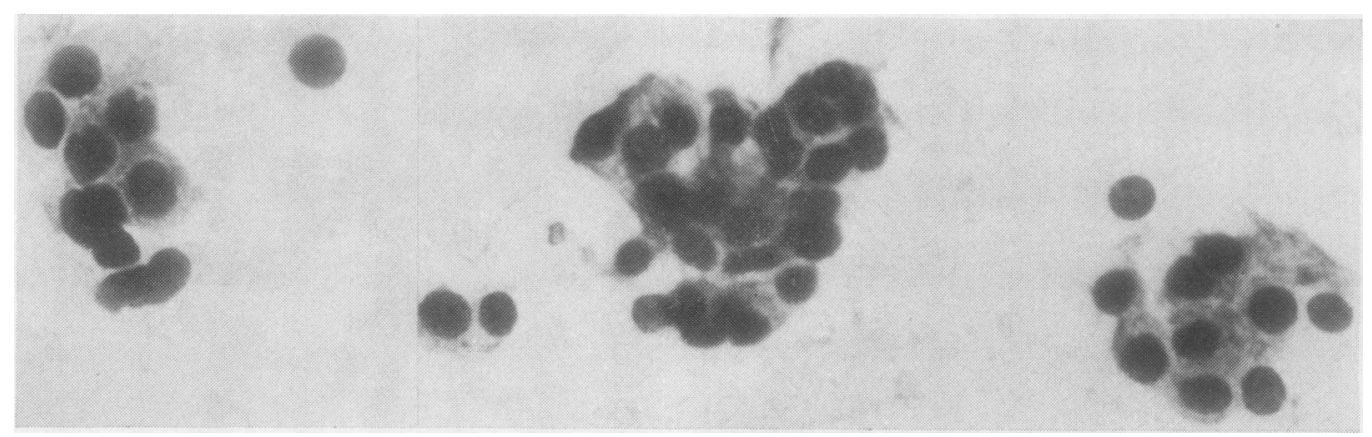

Fig. 8 Imprint of a parathyroid gland showing small groups of uniform, dark cells on a clean background. (Haemutoxylin and eosin $\times 400$ ) 
readily apparent-the normal lymphocytes and the neoplastic cells. The malignant features of the neoplastic cells, such as nuclear moulding and pleomorphism, are more clearly discernible here than on frozen section. Furthermore, the neoplastic cells show a tendency towards cohesiveness, the so-called 'clustering' phenomenon, while the lymphoid cells are dispersed.
TO DISTINGUISH PARATHYROID TISSUE

FROM OTHER SPECIMENS SUBMITTED AS POSSIBLE PARATHYROID GLANDS DURING PARATHYROID EXPLORATION

This aspect of the application of the imprint technique has been fully discussed by Silverberg (1975). In the present series, a total of 64 specimens was submitted during parathyroid exploration, including 47 para-

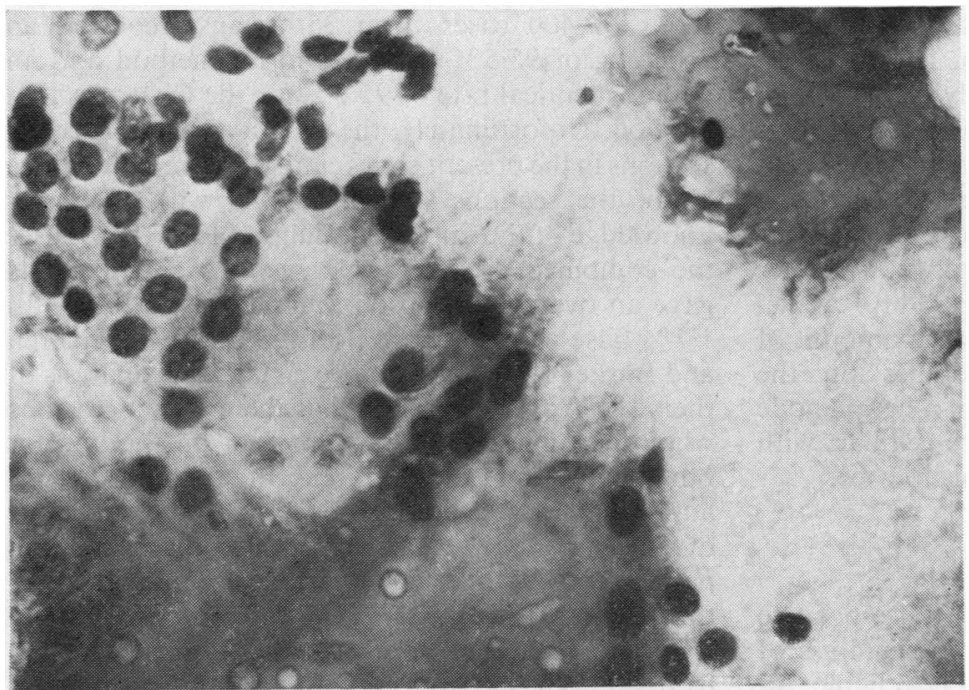

Fig. $y$ Imprint of thyroid tissue showing larger groups of cells than in Fig. 8. Note presence of amorphous, eosinophilic globules in the background. (Haematoxylin and eosin $\times 400)$

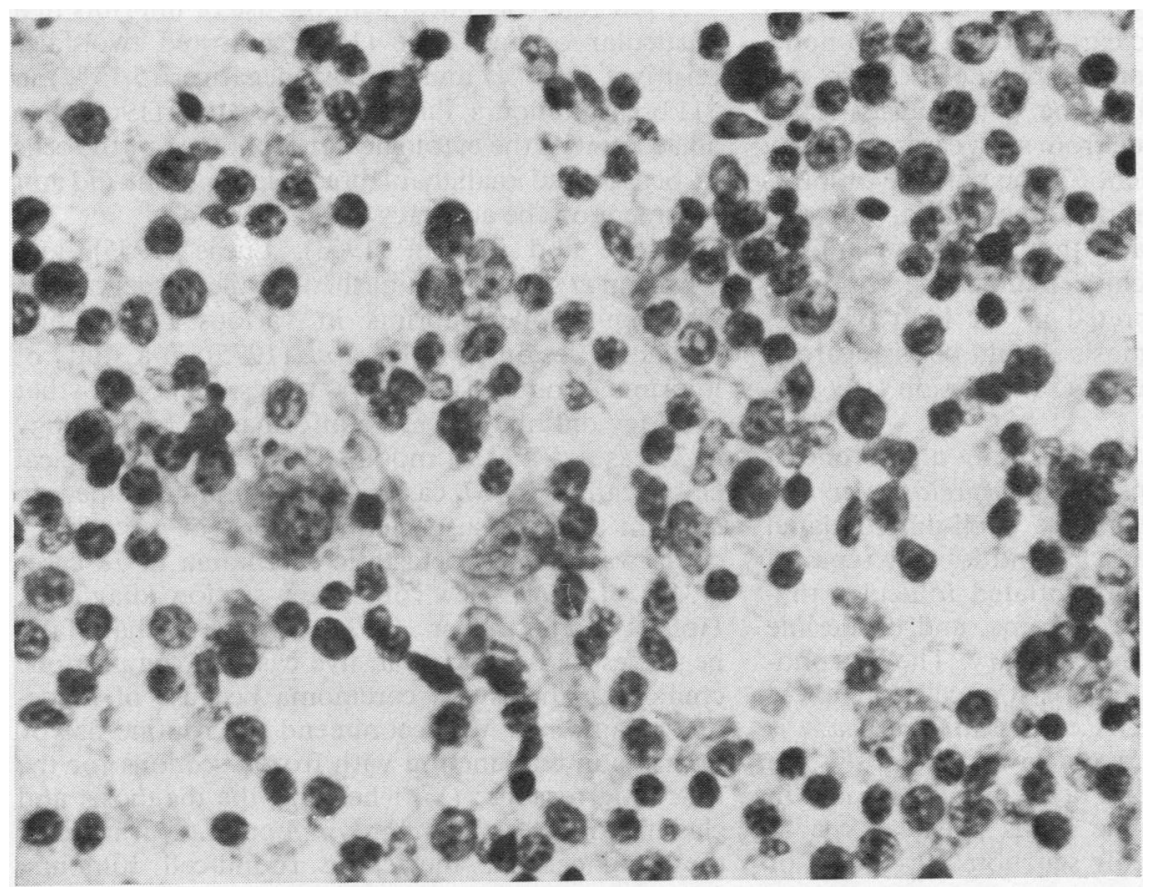

Fig. 10 Imprint of $a$ benign lymph node showing a variety of lymphocytes at various stages of maturity and phagocytic histiocytes. (Haematoxylin and eosin $\times 370$ ) 
thyroid glands, nine lymph nodes, five thyroid fragments, and three adipose tissue fragments. All of these specimens were correctly identified by the imprint technique (Table 1). In one case, frozensection interpretation was uncertain as to whether the specimen was a lymph node or a parathyroid gland. But imprint examination identified the specimen correctly as lymph node.

Figure 8 is an imprint of a parathyroid gland, which shows single, dispersed cells as well as small clusters of cells with acinus formation. The nuclei are darkly stained, round or oval, slightly larger than a lymphocyte, bordered by pale staining eosinophilic cytoplasm. The imprint has a relatively clean background. Figure 9 is an imprint of a thyroid gland showing cells morphologically similar to those of the parathyroid but which tend to arrange in larger sheets and exhibit more nuclear variability. A distinctive feature is the presence of a large amount of amorphous eosinophilic colloid globules on the background. Figure 10 is an imprint of a lymph node which is characteristically much more cellular, with easily identifiable lymphocytes and histiocytes.

\section{Discussion}

The low percentage $(0.24 \%)$ of false-positive diagnoses in this study suggests that a diagnosis of malignancy by the imprint method is reliable. In instances when a lesion is grossly malignant, for example, most cases of mammary carcinoma and many cases of metastatic carcinoma in lymph node, especially when the primary cancer site is known, it is necessary only to confirm the pathologist's gross impression. Imprints made from such cases, if clearly positive, would be sufficient for the purpose of intraoperative diagnosis. On the other hand, our $6 \%$ false-negative rate indicates that a negative imprint does not necessarily exclude malignancy. Imprints should always be interpreted in the light of gross findings; a negative diagnosis should be disregarded if the gross appearance of the lesion suggests malignancy.

False-negative reports are generally due to one of the following two reasons: (a) Interpretative errors: These occur in cytologically well-differentiated tumours, including the tubular and lobular types of breast carcinoma, well-differentiated follicular thyroid carcinoma, low-grade sarcoma, and borderline malignant cystadenoma of the ovary. The morphological changes of the neoplastic cells in these tumours are often subtle. A conservative attitude is warranted in order to avoid over diagnosis. (b) Insufficient cells: There is a dense fibrous stroma in some tumours, such as the linitis plastica type of gastric carcinoma, markedly scirrhous carcinoma of the breast, Krukenberg tumour, Brenner tumour, granulosa-theca cell tumour, some fibrous soft-tissue tumours, and some skin tumours. In these cases the number of neoplastic cells transferred to the slide is insufficient to enable the observer to make a correct diagnosis.

Our overall accuracy rate of $93.6 \%$ for the imprint method compares favourably with those of other authors. Sakai and Lauslahti (1969), in analysing a series of 400 cases from 35 organs, reported an accuracy of $95.5 \%$ for the imprint method and an almost identical rate of $95.7 \%$ for the frozen-section method. Unfortunately, the accuracy rate for frozen sections in the present series cannot be evaluated since all of the sections were examined with the prior knowledge of the imprint findings. In our 1258 cases the combined use of frozen sections and imprints gave an overall diagnostic accuracy of $98.3 \%$, with $1.7 \%$ false negatives and no false positives. Pickren and Burke (1963) did not give a statistical analysis of their 1819 cases but noted that there were occasions when the tumour cells were present on the imprint but absent on the section. In such instances, additional sections almost always showed the focus of cancer. Mavec (1967) examined the imprints prepared from 100 tumours of various organs and found the diagnosis to be correct in 93 cases. Godwin (1976) found the technique applicable to all types of lesions from all organs. There were no false-positive reports in his 20 years' experience.

A few references deal with the use of imprints in a particular organ. Tribe (1965) reported two false positives $(0.65 \%)$ and 16 false negatives $(5.15 \%)$ in 311 breast tumours. Pilar and Rubenstone (1968) gave an account of the cytological morphology of the cells in benign and malignant breast lesions but did not comment on the accuracy of the method.

Moore and Reagan (1953), Lucas (1955), and Ultmann et al. (1958) published detailed observations of lymph node imprints in various benign and malignant lesions. Mathé et al. (1975), in a study of imprints from 141 lymph nodes, reported that cytology did not add more information to histology in 39 cases $(27 \%)$; it modified or helped histological classification in 67 cases $(48 \%)$; and it helped to confirm that the suspected diagnosis of reticulosarcoma was in fact metastatic carcinoma in 18 cases $(13 \%)$. In a review of frozen-section diagnosis, Holaday and Assor (1974) reported that false negatives had occurred in five cases of lymph node containing metastatic carcinoma because of inadequate sampling. We recommend the routine use of imprints in conjunction with frozen sections for the following reasons: (1) it helps in the diagnosis and classification of malignant lymphoma, (2) it helps in the diagnosis of metastatic round-cell tumours, 
which may simulate lymphoma, and (3) it reduces sampling errors.

Silverberg (1975), using the imprint technique, was able to distinguish with $100 \%$ accuracy parathyroid from thyroid and lymph node specimens. Our findings are similar to those of Silverberg. The technique is particularly useful when multiple specimens are submitted within a short period of time. If on imprint examination parathyroid can be ruled out, the specimen no longer needs to be weighed or frozen, thus saving a considerable amount of time.

In conclusion, imprint cytology and frozen section complement each other in ensuring accuracy in rapid tissue diagnosis. In certain situations the imprint method is superior to the frozen section method, but in $6 \%$ of our cases a correct diagnosis can be accomplished only by frozen-section examination. Pathologists using both techniques will be providing their surgical colleagues with a better service. Expertise in imprint interpretation accrues from correlating tissue and imprint cytopathology in one's routine daily work. A reference file of imprint slides with corresponding tissue sections should be maintained in the laboratory for teaching purposes. We concur with Bamforth's opinion that cytology should not be confined in a special department of its own but should be practised in the general laboratory (Bamforth and Osborn, 1958).

\section{References}

Ackerman, L. V., and Ramirez, G. A. (1959). The indications for and limitations of frozen section diagnosis. A review of 1,269 consecutive frozen section diagnoses. British Journal of Surgery, 46, 336-350.

Ackerman, L. V., and Rosai, J. (1974). Surgical Pathology, 5th edition, Chapter 14, C. V. Mosby, St. Louis.

Bamforth, J., and Osborn, G. R. (1958). Diagnosis from cells. Journal of Clinical Pathology, 11, 473-482.

Dudgeon, L. S., and Patrick, C. V. (1927). A new method for the rapid microscopical diagnosis of tumours, with an account of 200 cases so examined. British Journal of Surgery, 15, 250-261.

Godwin, J. T. (1968). Smears from tissue submitted for frozen sections. Acta Cytologica, 12, 85.

Godwin, J. T. (1976). Rapid cytologic diagnosis of surgical specimens. Acta Cytologica, 20, 111-115.

Holaday, W. J., and Assor, D. (1974). Ten thousand consecutive frozen sections. A retrospective study focusing on accuracy and quality control. American Journal of Clinical Pathology, 61, 769-777.

Lucas, P. F. (1955). Lymph node smears in the diagnosis of lymphadenopathy: A review. Blood, 10, 1030-1054.

Mathé, G., Pouillart, P., Schlumberger, J. R., and Paintrand, M. (1975). Cytology in the classification of diffuse non-leukaemic malignant lymphomata (lymphoand reticulosarcomata). British Journal of Cancer, 31, Supplement 2, 53-59.

Mavec, P. (1967). Cytologic diagnosis from tumour tissue using the "quick method" during operation. Acta Cytologica, 11, 229-230.

Moore, R. D., and Reagan, J. W. (1953). A cellular study of lymph-node imprints. Cancer, 6, 606-618.

Nakazawa, H., Rosen, P., Lane, N., and Lattes, R. (1968). Frozen section experience in 3,000 cases. Accuracy, limitations, and value in residency training. American Journal of Clinical Pathology, 49, 41-51.

Pickren, J. W., and Burke, E. M. (1963). Adjuvant cytology to frozen sections. Acta Cytologica, 7, 164-167.

Pilar, P. B., and Rubenstone, A. I. (1968). A correlation of breast imprints (stained by the method of Papanicolaou) and tissue sections. Acta Cytologica, 12, 462-472.

Sakai, Y., and Lauslahti, K. (1969). Comparison and analysis of the results of cytodiagnosis and frozen sections during operation. Acta Cytologica, 13, 359-368.

Shivas, A. A., and Fraser, S. G. (1971). Frozen Section in Surgical Diagnosis. Churchill Livingstone, Edinburgh and London.

Silverberg, S. G. (1975). Imprints in the intraoperative evaluation of parathyroid disease. Archives of Pathology, 99, 375-378.

Suen, K. C., Yermakov, V., and Raudales, O. (1976). The use of imprint technique for rapid diagnosis in postmortem examinations. American Journal of Clinical Pathology, 65, 291-300.

Tribe, C. R. (1965). Cytological diagnosis of breast tumours by the imprint method. Journal of Clinical Pathology, 18, 31-39.

Ultmann, J. E., Koprowska, I., and Engle, R. L., Jr. (1958). A cytological study of lymph node imprints. Cancer, 11, 507-524. 